\title{
The Analysis on the Cultural Creativities, Itinerary and Field Shaping of the Indigenous People in Taiwan - Taking the Laiji Tribe and the Tjimur Tribe for Example
}

\author{
Meng-Ling Lay, Shu-Hua Gao, and Su-Ping Tan
}

\begin{abstract}
After tourism prevalence, the tribes of the indigenous people and their domains has become the tribes and marketplaces of cultural creativities. To satisfy the demands of touring and sightseeing activities, the itinerary planning is one of the significant factors to attract tourists. Itinerary design is inclusive of some service items like local traffic, lodging and relevant touring activities. This study is mainly aimed to focus on the subjects of empirical analysis, the Laiji Tribe and the Tjimur Tribe. The study is conducted by means of field research and literature review to explore the itinerary programming of these two places after they have become the tourism-oriented communities. Also, with this study, it is available to develop the itinerary programming and raise the suggestions for the process transformed from the traditional fields into the fields of cultural creativities.
\end{abstract}

Index Terms-Space of cultural creativities, tourism of indigenous people, itinerary programming.

\section{INTRODUCTION}

The cultural particularities of the indigenous people in Taiwan have become the major locomotive to develop the industries of cultural creativities among the indigenous people. Through the overall community construction and the promotion of local activities, the indigenous people make the original living space under the development of cultural economy gradually turn into the fields of cultural creativities featured with economic efficiency. During such a transformation process, what the spatial fields must experience is a qualification process with interaction and re-positioning.

Due to the influence of tourism prevalence, the indigenous people in Taiwan have made numerous tribes become the tribes featured with cultural creativities. Actually, the cultures of the indigenous people abound in their particularities and fascination. The traditional fields are coexisting with the natural space and the cultures of the indigenous people in Taiwan are prolifically vested with cultural capital and natural landscapes. As the definition proposed by Huang, Huang-Xiong [1], the cultural industries of the indigenous people mean the relevant issues of the domestically tribal humanities, history, handicrafts and natural ecology and through the tribal production, it is also involved with the relevant cultures like life and ecology with the indigenous tribes to ensure their industrial subjectivity,

Manuscript received July 27, 2013; revised September 29, 2013.

Shu-Hua Gao is with the Southern Taiwan University of Science and Technology, Taiwan (e-mail: ma1j4228@stust.edu.tw). constrict the tribal economic growth and enhance the industries associated with the tribal cultures.

Most tribes of the indigenous people in Taiwan are distracted in the areas with abundant natural resources. These tribes are rich in their own cultural particularities and the tribal communities are exactly the optimal candidate for tourism with the most powerful potential of humanities and ecological itinerary. However, these touring activities are involved with the environmental protection and cultural preservation. Such conditions drive the indigenous people in Taiwan to put more thoughtful deliberation on the cultural dimensions. Cultural capital is one of the important bases to develop the industries of cultural creativities and it is an element fairly equivalent to the entire body of knowledge, capacities and seniority. In the earlier society, people receiving formal schooling, knowledge or skills meant the people with cultural capital. Currently, personal manners and the cultural assets owned by people can be held as the cultural capital including personalities, talents, upbringing, education, heritage, degree, diploma, cultural goods and services [2].

In the domains of the indigenous people with the domains developed into the space of cultural creativities, the traditional domains and natural landscapes of the indigenous people have become the attracting elements for touring activities. The traditional fields are opened for tourism. For example, festival activities, the holy land and hunting have become the opened space due to the demands of itinerary programming allowable for sightseeing and experiencing.

During the process with the transformation into the itinerary fields of cultural creativities, some things initially foreign to these traditional spaces and fields like interpretive signs, attraction signs and environmental identification marks are established. Traditional tribes have become one of the major trends to serve for touring activities. During the process to found the itinerary domains and fields of cultural creativities, the original traditional space must be abandoned and it is required for thoughtful deliberation onto the influence and transformation after these domains and fields are opened. Herein, with the aforesaid two examples of the tribes of indigenous people, this study is meant to explore the transformation with the traditional domains of the indigenous people changed into the itinerary fields of cultural creativities.

\section{RESEARCH PURPOSES}

Taking the Taiwan Laiji Tribe (the Tsou) on the Alishan Township of the Chiayi County and the Tjimur Tribe of the Sandimen Township for example, this study is meant to 
explore the influence on the tribes and tourists exerted by the itinerary programming for tourists after traditional fields have developed into tourism fields. Also, the style is mainly by adopting the tribes of cultural creativities to analyze the overall spatial variability with the major research purposes detailed as below:

1) Explore the itinerary fields and field shaping of the tribes of cultural creativities among the indigenous people in Taiwan.

2) Compare the representative ways of the itinerary spatial fields between Laiji Tribe and Tjimur Tribe this indigenous people in Taiwan.

3) Explore the suggestions raised in the itinerary fields and field shaping of the tribal space of cultural creativities in the future.

\section{RESEARCH SUBJECTS}

In this study, the Laiji Tribe on Alishan and the Tjimur Tribe are served as the research subjects.

In 1980s', the tourism of the mountainside villages was directed by governmental township offices. After 921 Earthquake, the $\mathrm{Xi}-\mathrm{Ah}$ pace way was ruined and hiking tourists turns their destinations to adjacent natural scenic spots for touring activities. Thereafter, after the Alishan National Scenic Area Management Office was established, the Laiji Tribe was delineated as a part of this area. In 2002, the tribe, with the help of the National Taiwan Craft Research and Development Institute, promoted the activities to establish an art village and receive violently positive response. They also constructed the workshops with tribal particularities, the youth center, wild boar sculptures, hiking trails and pavilions in their tribe.

According to the similarity and variance of the residing areas and cultural representation, the Paiwan can be divided into the North Paiwan, Middle Paiwan, South Paiwan and East Paiwan [3].

The Tjimur Tribe is located at the Sandimen Township. The Paiwan is known as Se-Timor in their own language and located at the northeastern side of the Ai-Liao Stream. In terms of the historical literatures during the periods of the Qin Dynasty, Dutch Occupation or Japan Occupation, the Paiwan was never a closed community and they had been communicated with other ethnic groups with cultural diversities [4].

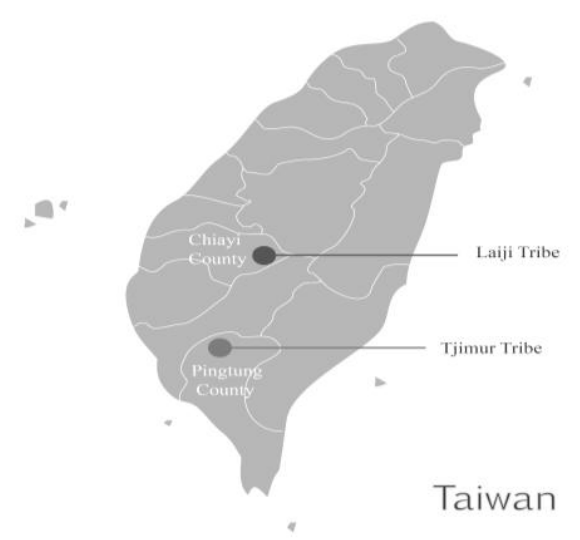

Fig. 1. The locations of the Laiji Tribe and the Tjimur Tribe
The history of the Tjimur touching the outside world was half a century. Earliest starting from the Japan Occupation Period, this area had developed its own industries of cultural tourism. Currently, it has become the political and cultural center of the Paiwan in the southern Taiwan. In view of the graphical site, it is also the center of the North Paiwan, a pivot of the political, societal, economic and cultural resources [5].

\section{LITERATURE REVIEW}

The scope of this study mainly focuses on the itinerary fields of cultural creativities at the Laiji Tribe and the Tjimur Tribe for the analysis of scientific literatures.

\section{A. The Touring of the Fields and Domains of the Indigenous People}

In 1987, because the martial law was abolished in Taiwan, the overall society had entered into a new development phase and the societal movement of the indigenous people was also mushrooming. The tribal consciousness was rising with their consideration backing to the ethnically tribal cultures available for touring activities. Also, in the late 1990s, under the impetus of numerous policies of cultural tourism, such thinking was exactly the key issue for the cultural industry development among local tribes. In the Challenge 2008 - the National Key Development Plan proposed by the Executive Yuan and the 6-Year-Plan of New Tribes of the Indigenous People (1992 1997), there were several development items to promote tourism industries, tribal hostels, tribal knowledge industries and tribal ecology. Additionally, due to tribal demands and the impetus of governmental policies, the local touring industries of the indigenous people have been thoroughly developed [6].

Recently, because of the influence caused by the industries of cultural creativities, the touring of spaces and domains have been prosperously developed. The tribes of the indigenous people also develop toward the industries of cultural creativities gradually. Therefore, there are numerous traditional fields and domains of the indigenous people with their development stepping into touring industries. During the process to develop toward the fields and domains of cultural creativities, they inevitably face the disappearance or transformation of numerous traditional space and fields wherein they also have to face some touring issues relevant to indigenous people. Actually, there are numerous policies and methods protecting the indigenous people with several museums established.

However, during the evolutionary process, the development shall be mainly aimed to attract tourists such as the dancing and singing performance of indigenous people different from their own tradition or the re-shaping of their living space but ignoring the true meaning therein. In view of their living ways, rice has replaced millet with the millet ceremony also disappearing. The place to connect with forefathers and tribal members also loses their initial functions. Additionally, the indigenous people also lose their living skills and traditional fields [7].

Furthermore, the development of touring activities also results in the overall transformations including economy, 
culture and ecology. The modern touring development drives the aboriginal cultures of the indigenous people changed into the development to become urban or modern with the spatial changes like stores for rent and the tribal performance zones [8]. Moreover, the rising hostels also become the touring products. When the tourism industries are developed, the interactive relationship between space and environment must be taken into consideration [9]. In the process for tourism planning, how to keep the aboriginal domains and fields, along with cultural heritage, featured in the newly developed domains and fields have become the critical issues for the indigenous people to develop their own tribes, tourism parks and marketplaces.

\section{B. Itinerary Programming}

As Lai-Guo-Ling[10] defined, itinerary programming is exactly the touring programs deliberately planned and designed by touring planners by exerting their best knowledge and tools to satisfy the demands of tourists before trip departure with the contents including transportation, meals, lodging and touring courses. Niu, Xiang-Rong [11] divided the itinerary into different levels like touring trips, customary trips, touring zones, accompanying staffs, service and trip distances.

The key points of ecological tourism are aimed to invoke the environmental experience and continuous sentiment of tourists through the design of the itinerary process. The ecological concepts are established through such experience and interactive processes in coordination with the experience of cultures, industries and humanities during the process with the environmental education emphasized by ecological itinerary achievable [12].

As J. T. Zhang [13] contended, the principles of the itinerary programming were divided into four items:

The principle of the market: Itinerary programming must take better control market trends and the supplies available for relevant to suppliers.

1) The principle with reasonable arrangements for touring spots: When over the itinerary courses are designed, attention should be paid to the reasonable framework and selection of three itinerary spots with the courses logically designed.

2) The principle of transportation arrangement: The service suppliers should take safety into the first consideration with reasonable transformation tools employed.

3) The principle with theming contents: The itinerary courses should be designed with specific themes to linkage the itinerary courses together. It is allowable for tourists to know much about the transformation of cultures, life or ecology among various touring spots in good coordination with the specific themes with the quality well ensured.

Although, in view of the operational ways of itinerary programming, the programming procedures involved with ecological touring activities and ordinary touring activities are roughly identical. In general, ordinary itinerary can be divided into 7 dimensions: target customers, the provision of tourism information, travel time constraints, lodging choices, seasonal weather, traffic conditions and budget. However, ecological tourism must take good care of ecology, environmental preservation and community welfare. Therefore, in the process of itinerary programming, aside from the aforesaid dimensions, the environment of hardware (the resource facilities available for touring packages)and the resource of software (narrators and local experiencing activities)must be taken into consideration to satisfy the demands of the ecological itinerary like experience, researches, understanding and learning [13].

\section{The Cultural Industries of Indigenous People}

In view of the article performance of the indigenous people in Taiwan, as J. C. Lin [14] proposed, to understand the cultural art of the indigenous people, it was required to shake off the long existing cages and explore the rooted and the true meaning behind the cultures to find the context with authentic meaning.

Most of the indigenous people in Taiwan are distributed in the places with abundant natural resources. The indigenous people are vested with prolific cultural particularities and these places are exactly the ones featured with the most powerful potential for the development of ecological itinerary. However, the tourism is involved with environmental protection and much more in cultural preservation. As such, the tourism development in the indigenous tribes is additionally featured with the thoughtful deliberation of the cultural dimensions.

Therefore, the 3-Year Plan of Economy and Industry Development of the Indigenous People proposed by the Council of Indigenous People of the Executive Yuan is designed with sixty guidance plans available for more aggressive effort including the guidance of the tourism industries, the guidance of three living conditions, the promotion of the industries of cultural creativities, the construction of the center of business foundation and marketing mechanisms, the promotion to protect intellectual creativities, the guidance for the business management of ethnic industries to facilitate the indigenous tribes for the development of the industries of cultural creativities [15].

In view of the cooperation between the tribal members and people outside, the itinerary of cultural creativities to shape their own cultural structures available for touring activities, can allow the cultural heritage of indigenous people aside from experiencing the art of the aboriginal tribes. However, in the shaping process, the key issue of this study focuses on whether the craftsmanship of the indigenous cultures can be well kept without destruction happening.

\section{RESEARCH METHOD}

This research was conducted by means of the review of historical literatures, field surveys and interview.

\section{A. The Method of the Review of Historical Literatures}

The method of the review of historical literatures means a method purposed to investigate history and its evolution with the technical levels focusing on any facts happened in the past. As S. T. Chen [16] proposed, such a researching method is vested with four different features:

1) The feature of time: The origin, rising and disappearance of an event are always traceable. The historical 
researching method is based on time-axis with the positioning of historical facts.

2) The feature of space: The appearance, occurrence inevitability and the sizes of the space and geographical layout of an event are all corrected mutually.

3) The feature of interaction: Human beings, time and space are correlated mutually arising complex factors of the event.

4) The feature of change: In human history, any event is always affected by different time points and spaces to bring about changes.

The historical method is conducted to track the past historical facades of tribal space and applied domains. From historical information, by using the methods of observation and measurement, the historical material is systematically organized and explained to bring about the correlation to separately independent historical facts as the basis to understand the present and predict the future. Especially, the spatial changes happening to tribal domains is exactly the key interest in event exploration mentioned in this research.

\section{B. The Method of Field Surveys}

With long-term practical experience or the involvement of tribal activities, it is meant to observe and understand the substantially existing phenomenon in tribal life. Meanwhile, by referring to the compiled results from past scientific literatures to fulfill the deficiency in scientific literatures, the in-depth tribal interview for the subjects of the case study is conducted to explore the social relationship happening to the changing records of tribal domains and processes [17]. Field surveys are meant to obtain the in-depth or fact-feedbacking information or oral records with the appropriate interview to collect and observe current culture, society and local styles.

\section{The Method of Interviewing}

Interview means the interaction between two different roles. Through the dialogues of asking and answering, the relevant information is obtainable. When the interview is conducted, some nonverbal intentional expression like the facial countenance, tones and postures of the interviewees are also worthy of exploration. Through interviews, some new discussion issues can be found or arisen to serve as the major measuring tool for researches or the supplementary tools during researching processes, or the material applicable to subsequent researching follow-ups. Also, it is easier to enter the core issues deeply. When conversing with interviewees, it is available to evaluate the reliability and authenticity of the answered words from interviewees through interaction [18]. Additionally, it is suitable for special subjects and environment effectively enhancing researching reliability and validity. It can also indirectly improve the response capabilities of the interviewer to train observatory capabilities and the mindsets for problem solving.

\section{RESEARCH ANALYSIS}

Through the analysis of historical literatures, field surveys and interview, it can be found in this study in the shaping of the itinerary fields of the cultures of the indigenous people, the major research subjects we mainly explore are exactly the
Laiji Tribe and the Tjimur Tribe with the shaping of the itinerary fields of their cultural creativities described as below.

\section{A. The Shaping of the Itinerary of Cultural Creativity at the Laiji Tribe}

Because the Laiji Tribe was fiercely affected by the 88 Flood, 66\% farming lands have been lost. The key crops (shoots) are also badly affected. In addition, the used-to-be prevalent ecological tourism of the Laiji Tribe also gradually loses their customer resources due to inferior traffic conditions deeply impacted by the natural disasters. The tribal residents are now just relying on agricultural affairs to make their basic living. It can be seen through the experimental investigation the Laiji Tribe is merited with the gorgeous natural scenes of the Mount Alishan. It is also featured with some touring resources like the handicraft workshops of particularities, typically a tribe having the natural scenery and art. Under the changes of the era, currently this tribe cannot lead a life in a totally traditional economic model in their lives. The Laiji Tribe is now featured with the touring resources of both the natural scenes and art. Through propaganda and design, this tribe has developed into the scenic spots with the coexisting interaction between humans and the Mother Nature.

Currently, the residents of this Laiji Tribe mainly engage in agricultural affairs. After the itinerary fields of cultural creativities have been created, tribal residents start to establish hostels, handicraft stores and the experiential activities of tribal DIY handicraft. Also, the local tribal residents serve as touring narrator to interpret the tribal relics and adjacent geographical landscapes for tourists. The tribe can keep the spatial fields with much more traditional atmosphere wherein the environmental identity marks never showing in the past start to emerge. In view of itinerary programming, the planning arrangement of the Laiji Tribe belongs to interact and experience ways mainly focusing on wood handicrafts. In the itinerary, it is available for tourists to experience the meals with tribal flavors and handicraft recreation. In the space of itinerary, it is allowable for tourists to experience the spatial fields of local tribal residents such as the houses, decorative stuffs and spatial adornment.

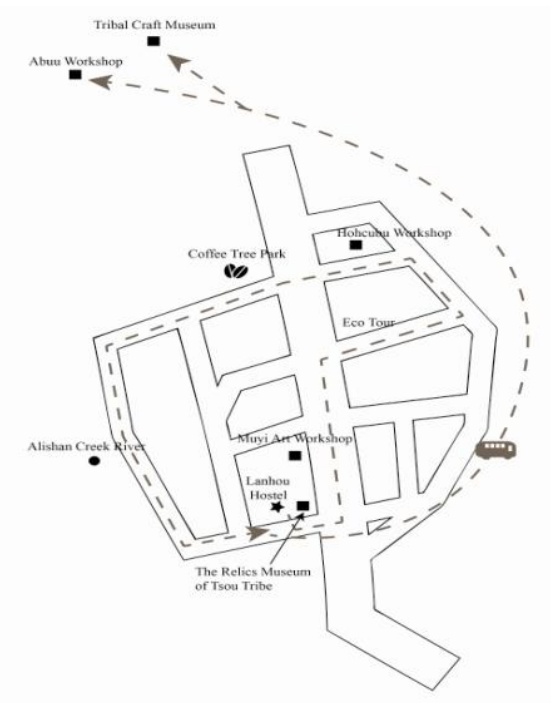

Fig. 2. The itinerary fields of cultural creativities of the Laiji Tribe. 


\section{B. The Shaping of the Itinerary of Cultural Creativity at the Tjimur Tribe}

The Tjimur Tribe is located at the Tjimur Township known as Se-Timor northeastern to the Ai-Liao Stream. In view of the village environment, the tourism industries have been developed for 20 years nearly and these have become the critical parts in describing the industrial transformation of the Tjimur Tribe. The Tjimur Tribe is exactly the location of the governmental office of the Tjimur Township. Meanwhile, it is also the major zone to develop cultural industries for past three years. The Tjimur Marketplace is a critical locale with the governmental effort firstly focusing on the economy of the indigenous people. For the past few years, with the continuous subsidy to revive cultural industries, the reviving programs of agricultural villages, the employment project proposed by the Council of Labor Affairs and the governmental subsidy of the multiple employment projects, it also invisibly triggers the development of some cultural industries clothing, Ryukyu glass beads and clay pots [4].

In terms of itinerary programming, in 2010, the Pingtung University of Science and Technology was invited by the Tjimur Township Office and the Tjimur Art Association of Cultural Industries to develop the first ecological itinerary known as the Cultural and Ecological Easy Itinerary - the Classic of Ryukyu Glass Beads \& the Hometown of Black Kites [19]. In 2012, the itinerary programming for this cultural and ecological journey has developed into the itinerary to experience various tribal styles, archery, making Ryukyu glass beads and the understanding the knowledge of animal conservation.

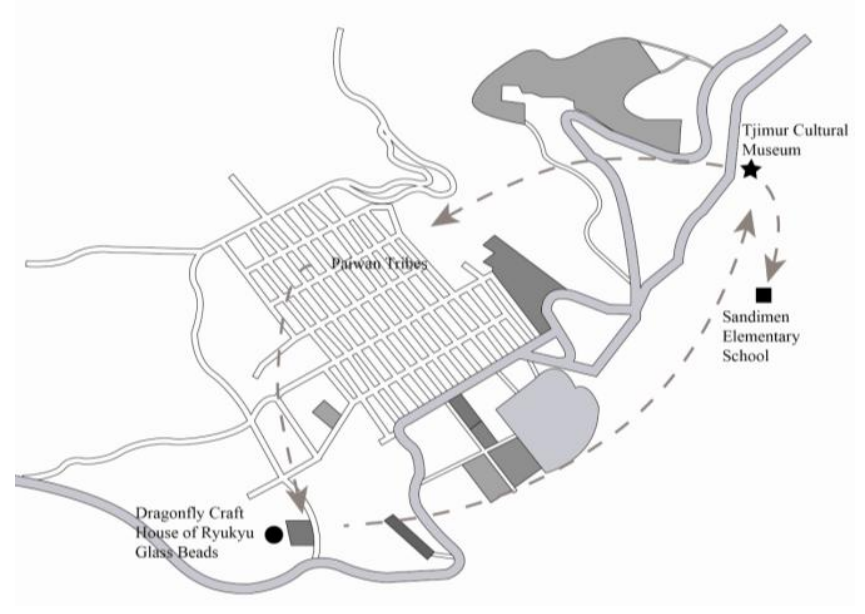

Fig. 3. The itinerary fields of cultural creativities of the Tjimur Tribe.

Currently, in the Tjimur Township, there are some cultural stores or workshops like the Dragonfly House \& Unique Food, the Sand Flow Art Space of Ryukyu Glass Beads, the Er-Ge Handicraft Workshop, and the Dageifali Gourmet Place \& Workshop to stably develop relevant cultural industries in a large scale like Ryukyu glass beads, clothing, sculptures and the gourmet of the indigenous people. Simultaneously, it also provides the employment opportunities for Tjimur residents. In addition, some workshops like the Dragonfly House and the Sand Flow Art Space of Ryukyu Glass Beads also spend their aggressive effort to cooperate with the government enhancing the brand visibility and expanding the markets of cultural commodities. At present, the Tjimur Township views the Ryukyu glass beads as the major development industries of cultural creativities. Therefore, the itinerary programming is also mainly themed with the experience of making Ryukyu glass beads.

\section{The Comparative Analysis of the Tribal Itinerary Fields of Cultural Creativities}

In accordance with the principle with theme contents in itinerary programming proposed by J.T, Zhang [13], some themes should be highlighted through itinerary programming to run through the overall touring journey. It is allowable for tourists to understand the revolution of culture, life or ecology at every scenic spot. Meanwhile, various touring facilities should be in harmonious coordination with the theme touring activities. In this study, the comparison of the itinerary programming between the Laiji Tribe and the Tjimur Tribe with the activity titled <Experience - The Enjoyment Heading South>[20] held by the National Tainan Living Art Center is described in Table I.

The touring activities of the tribe, the original domains strongly featured with exclusivity have become a part of itinerary programming. Due to governmental planning activities, the Tjimur Tribe has been obviously changed into the place strongly featured with commercial atmosphere with the reconstructed tribal space even especially designed for tourists. The local traditional fields are also gradually changed into the space with economic value.

Comparatively, the Laiji Tribe is featured with stronger originally tribal styles. Despite no touring environmental signs, commercial stores and commerce organizations found, the natural space can be well kept in a coexisting way and this is also the most significant difference between two different tribes.

Currently, the increasing fever with local people highly emphasizing leisure tourism, tribal development becomes inevitable. In the process, the development of cultural, natural and culturally creative fields should be well underscored. Actually, the development of the fields of cultural creativities is closely correlated to tourism itinerary.

\section{CONCLUSION}

\section{A. The Fields of Cultural Creativities}

Because the indigenous people in Taiwan are advantaged with abundant culture along with geographical conditions, most tribal environments are natural landscapes. When the traditional fields of the tribe are shaped as the itinerary fields of cultural creativities, the cultural fields of the indigenous people are involved with the natural environment and such a situation is quite different from the natural space built in urban areas. Actually, reconstructed space is filled with contradiction without the resonance in correspondence to the space. The traditional space of the indigenous people can be in better coordination with the Mother Nature. 
TABLE I: THE COMPARATIVE ANALYSIS OF THE ITINERARY FIELDS OF CULTURAL CREATIVITIES.

\begin{tabular}{|c|c|c|c|}
\hline & & Laiji Tribe & Tjimur Tribe \\
\hline \multicolumn{2}{|c|}{ Itinerary Facility } & $\begin{array}{l}\text { 1. Restaurant } \\
\text { 2. Hostel } \\
\text { 3. Tribal Craft Workshop } \\
\text { 4. Mass Transportation Tools } \\
\text { 5. Natural Landscapes }\end{array}$ & $\begin{array}{l}\text { 1. Restaurant } \\
\text { 2. Hostel (Narrated by Locals) } \\
\text { 3. Craft Workshops of Ryukyu Glass Beads } \\
\text { 4. Mass Transportation Tools } \\
\text { 5. Marketplaces } \\
\text { 6. Cultural Museum } \\
\text { 7. Ecological Park }\end{array}$ \\
\hline \multirow{9}{*}{ 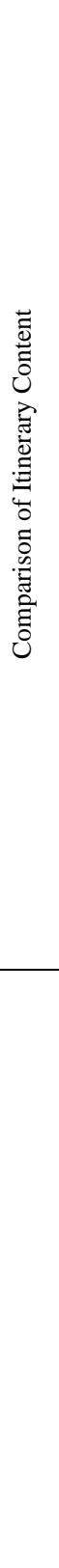 } & Itinerary & $\begin{array}{l}\text { Departing from the Lanhou Hostel } \rightarrow \text { The Journey of } \\
\text { the Reconstruction of Craft Tribe } \rightarrow \text { Hohcubu } \\
\text { Workshop } \rightarrow \text { Muyi Art Workshop } \rightarrow \text { The Relics } \\
\text { Museum of Tsou Tribe } \rightarrow \text { Flavor Meal (Lanhou } \\
\text { Hostel) } \rightarrow \text { Understand Tribal Environment } \rightarrow \text { Tribal } \\
\text { Craft Museum(DIY Experience) } \rightarrow \text { Abuu Workshop } \\
\text { (DIY Experience) }\end{array}$ & $\begin{array}{l}\text { Departing from the Tjimur Cultural Museum } \rightarrow \text { The } \\
\text { Insightful Narration of the Paiwan Tribes } \rightarrow \text { Dragonfly } \\
\text { Craft House of Ryukyu Glass Beads(DIY } \\
\text { Experience) } \rightarrow \text { Flavor Meal(The Unique Cafeteria) } \\
\rightarrow \text { Sightseeing the Tjimur Cultural Museum } \rightarrow \text { Joining } \\
\text { the tribal festival activities of the Sandimen } \\
\text { Elementary School }\end{array}$ \\
\hline & Guide Narration & Yes & Yes \\
\hline & Content Theme & $\begin{array}{c}\text { The Journey of Tribal Reconstruction and the Color } \\
\text { Painting of Wood Boars }\end{array}$ & $\begin{array}{c}\text { The Journey of Tribal Cultures and the Experience of } \\
\text { Making Ryukyu Glass Beads }\end{array}$ \\
\hline & Market & $\begin{array}{l}\text { Creation - Understanding the space of tribal } \\
\text { reconstruction and the current status of cultural } \\
\text { creativities }\end{array}$ & $\begin{array}{l}\text { Creation - Understanding the space of tribal } \\
\text { reconstruction and the current status of cultural } \\
\text { creativities }\end{array}$ \\
\hline & Transportation & Coach / Taking the Alishan Bus to the destination & Coach / Taking the Pingtung Bus to the destination \\
\hline & $\begin{array}{l}\text { Organizations } \\
\text { of Tourism } \\
\text { Spots }\end{array}$ & $\begin{array}{l}\text { The space is smaller with every scenic spot available } \\
\text { for walking trips to save time in a convenient way } \\
\text { without the worry of bad weather. }\end{array}$ & $\begin{array}{l}\text { The space is larger with every scenic spots linked by } \\
\text { transportation tools. It is required to take weather into } \\
\text { consideration with less convenience. }\end{array}$ \\
\hline & Spatial Layout & $\begin{array}{l}\text { 1. There is no narrative or identifying signs available } \\
\text { in the tribe. For example, it is difficult for guide } \\
\text { narrators to confirm their locations and } \\
\text { destinations. } \\
\text { 2. Houses are separately distributed and featured with } \\
\text { different styles, simple, unique and abundant in } \\
\text { ethnic colors. } \\
\text { 3. The relic museum is a private asset lacking the care } \\
\text { with dedicated personnel. } \\
\text { 4. DIY experience space is integrated with home } \\
\text { environment, workshops or craft studios. }\end{array}$ & $\begin{array}{l}\text { 1. Guide MAPS are widely distributed in the } \\
\text { village with clear descriptions unnecessary for } \\
\text { narrators. } \\
\text { 2. Houses and stores are neatly distributed. The } \\
\text { houses are mostly decorated with luxury appearance } \\
\text { but murals are designed in a simple way. } \\
\text { 3. Every neighborhood zone is separately designed } \\
\text { with their own unique image in the entrance gate } \\
\text { abundant in sightseeing atmosphere. } \\
\text { 4. The cultural museum is a public asset under the } \\
\text { custody of dedicated personnel. } \\
\text { 5. It is integrated with resultants and craft stores. }\end{array}$ \\
\hline & Advantages & $\begin{array}{l}\text { 1. The itinerary space with traditionally natural } \\
\text { itinerary is well conserved. } \\
\text { 2. Because of no specific narration, it is unavailable } \\
\text { for tourists to obtain the knowledge and opinion } \\
\text { different from their past experience. } \\
\text { 3. Craftsmen share their working experience in } \\
\text { creativities. } \\
\text { 4. Well-prepared lodging facilities } \\
\text { 5. The narration can be flexibly adjusted by narrators } \\
\text { due to their own experience. } \\
\text { 6. Original space is better kept. }\end{array}$ & $\begin{array}{l}\text { 1. Because of the neat space layout, it is difficult for } \\
\text { tourists to get lost. } \\
\text { 2. Suitable for one-day itinerary } \\
\text { 3. No narration required and allowable for better } \\
\text { understanding of local customs and styles. } \\
\text { 4. Strongly featured with the concepts of cultural } \\
\text { creativities } \\
\text { 5. Suitable for the tourists fond of shopping }\end{array}$ \\
\hline & Disadvantages & $\begin{array}{l}\text { 1. Required for narration to understand the touring } \\
\text { sport } \\
\text { 2. Weakly featured with the marketing concepts for } \\
\text { the commodities of cultural creativities } \\
\text { 3. Lacking professional narrators } \\
\text { 4. Lacking indicative and interpreting signs at scenic } \\
\text { spots }\end{array}$ & $\begin{array}{l}\text { 1. Excessively featured with commercial atmosphere } \\
\text { 2. More reconstruction facilities dedicated to tourism } \\
\text { 3. Ill-prepared lodging facilities } \\
\text { 4. Rigidly arranged narration } \\
\text { 5. Traditional space invisible }\end{array}$ \\
\hline
\end{tabular}

Additionally, the living art of the indigenous people also establishes the foundation for the transformation of the fields of culture recreate itinerary. For indigenous people, art and culture permeate in their daily life. However, after affected by commercial economy, these cultural arts are probably forced to be extinct. Therefore, the indigenous people can develop and inherit the cultural arts of various ethnic groups through itinerary programming. As such, itinerary programming is not only dedicated to tourists. For organizers, they have to thoughtfully think about the message really to be delivered. In this study, the itinerary fields of cultural creativities between the Laiji Tribe and the Tjimur Tribe are concluded as below:
1) Laiji Tribe: In the itinerary of the Laiji Tribe, tourists can easily interact with local residents. The craft workshops create the space of no commercial atmosphere like ordinary stores. Tourists are allowed to chatter with craftsmen and conduct DIY experience. In the sightseeing process, tourists sense less commercial atmosphere in their trips. Although there is no clear indicative and narrative sign, yet through the narration of local residents, tourists can immerge themselves deep in the experience of cultural creativities in such a space. For tourists, the sightseeing spots like local residences sell numerous handicrafts giving the amiable image to tourists.

Despite no commercial atmosphere due to no 
identification planning available for the environment, it can still result in the cognition gaps in the mind of tourists. Such fields of the itinerary of cultural creativities should be guided by local residents. In the process for the Laiji Tribe to change into the fields of cultural creativities, aside from the influence caused by natural disasters, artificial reconstruction also continuously creates new itinerary space. Because maintaining the spatial fields with more tradition, the Laiji Tribe makes more natural ecology and itinerary of cultural creativities kept in the local environment.

2) Tjimur Tribe: The Tjimur marketplaces are filled with several commercialized layouts and facilities. Also, local craftsmen affirm if the development of cultural creativities is necessary for the Tjimur Township, then they should equip themselves with the special opinions of historical and cultural background. In terms of the way how to make culture changed into industries and infused into daily life, in this study, we interview Miss Shi, Xiu-Ju who has engaged in the promotion of Ryukyu glass beads for thirty years. She indicates the culture actually exists in our daily life.

As Miss Shi, Xiu-Ju contended, the so-called industries of cultural creativities means the original core value is changed into the reliance of our life, but the substantial key lies in the cultural spirit. It cannot be changed and receives no change. Their reverence to Ryukyu glass beads includes the representation in skills with the very natively ancient skills to demonstrate this art and this is exactly the lesson with the Ryukyu glass beads stepping on the traditional dimensions. In terms of advantages, the traditional culture of the Paiwan Tribe are actually re-shaped and infused into daily life. Such re-shaped results also become the theme features of street stores. However, the payable sightseeing visits to the cultural museum due to commercial activities and the rigidly regulated norms also make the itinerary of the Tjimur Tribe filled with commercialization elements.

\section{B. Conclusion and Suggestion}

With the comparison of the marketplaces and tribes of cultural creativities, it can be divided into the itinerary space of cultural creativities after commercialization and the itinerary space of cultural creativities without commercialization. In the itinerary space after commercialization, the roles assumed by tourists are something closer to consumers. When tourists touch the commercialized culture, the sense of distance is easily arisen and even the intention of tourists to understand the culture is reduced. Instead, in the itinerary space after commercialization, tourists' interaction and resonance with craftsmen can be obviously seen.

Although both local and international the Laiji Tribe and the Tjimur Tribe develop their own tourism industries, yet they show the difference in demonstrating the commercialized atmosphere with two different kinds of itinerary fields of cultural creativities arisen. In view of the craft workshops at the Tjimur marketplaces, craftsmen acts the roles more like merchants and vendors. Such a situation also creates a gap between tourists and local residents and it is exactly the critical gap whether the itinerary fields of cultural creativities are affected by regulated commercialization. Probably, the upcoming research effort can be spent in thinking about the way how to combine the advantages of both the tribes to enhance the cultural in-depth heritage and the development of economic value.

\section{REFERENCES}

[1] H. X. Huang and C. C. Huang, The Total Experience of the Cultural Industries of the Indigenous People, Taipei: the Yuang-Liu Publisher, 2004.

[2] S. H. Zhou and J. Q. Ye, "The art athletic of the society fields: the relationship between the new generation artists in Taiwan and the exhibition space," the Dissertation for the Master's Degree of the Graduate Institute of Art and Design, Yuan Ze University, 2009.

[3] W. H. Chai, "The planning research on the planning for the ecological tourism themed with the Paiwan culture: Taking the Tjimur on Pingtung for example," the Dissertation for the Master's Degree of the Graduate Institute of Landscape Architecture and Recreation Management, the National Pingtung University of Science and Technology, 2009.

[4] Y. M. Guo, "The commercialization of the Paiwan clothing at Tjimur and its transformation in meaning," the Dissertation for the Master's Degree of the Graduate Institute of Anthropology, the Natural Tsing Huang University, 2006.

[5] G. M. Jiang, "The modern identity and transformation of the cultural industries at Tjimur," the Dissertation for the Master's Degree of the Graduate Institute of Ethnic Relations and Cultures, National Dong Hwat University, 2003.

[6] J. R. Huang. (May 31 ${ }^{\text {st }}, 2013$ ). The Trivial Tourism Industries of the Indigenous People. Encyclopedia of Taiwan. [Online]. Available: http://taiwanpedia.culture.tw/web/content?ID=11171.

[7] G. Y. Lin, "The interlace of tourism and traditional culture of the indigenous people: Taking the amis Citung Tribe on Taitung for example," the Dissertation for the Master's Degree of the Graduate Institute of Austronesian Culture, National Taitung University, 2010.

[8] Y. R. Chen, Y. M. Qiu, and H. R. Tang, "Explore the perception of societal impact of the tourism in the Wulai indigenous tribe on the Taipei county in a multidimensional scaling way," The Hwa Kang Geographical Journal, vol. 25, pp. 67-86, 2010.

[9] Q. L. Zhang, J. C. Zhang, and Q. Y. Gao, "The brief status of the hostels of the indigenous people - taking the Wutai township of the Pingtung county for example," The Journal of Sustainable Development and Management Strategy, vol. 1, no. 1, pp. 25-32, 2009.

[10] G. L. Lai, "The study on the itinerary programming of foreign journeys provided our local travel agencies: taking the journeys of new Zealand and Australia for example," the Dissertation for the Master's Degree of the Graduate Institute of Tourism Industries of the Chinese Culture University, 1994.

[11] X. R. Niu, The Business Management of Tourism, the Yang Chih Publisher, 2005.

[12] X. R. Lin, "A small journey of forest ecology," The Album of Forest Ecological Journey, vol. 38, 2012, pp.15-20.

[13] J. T. Zhang, The Business Management of Travel Agencies, Taipei: the Farseeing Publisher, 2005.

[14] J. C. Lin, The Field Notebook of the Art of the Indigenous People, Taipei: the Artist Publisher, 2002.

[15] The 3-Years Economic and Industrial Development of the Indigenous People (2010 2012), the Council of Indigenous Peoples, Executive Yuan, Unpublished, 2007.

[16] S. C. Chen, The Design of Researching Methods, Taipei: The Chuanhua Publisher, 2010.

[17] H. Y. Qu, The Methods of Investigation and Research, Taipei: The Sanmin Publisher, 2007.

[18] L.Y Ruan, The Design of Researching Methods, Taipei: The Chuanhua Publisher, 2010.

[19] Department of Forestry Students Planning Eco-Tourism of Tjimur Tribe and the Tjavang Tribe Issuance Meeting, Community Forestry Eco-tourism, July $20^{\text {th }} 2013$.

[20] Experience-The Enjoyment Heading South. The National Tainan Living Art Center. (July $31^{\text {st }}$ 2013). [Online]. Available: http://www.tncsec.gov.tw/ntnlac/Code/ActInfo11.aspx?id=a9feb267d043-4f5d-8d48-05c506faabf6. 


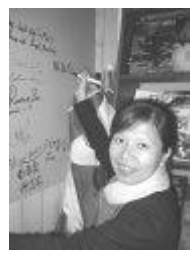

Meng-Ling Lay is a Ph.D. of the Graduate School of Design at the National Yunlin University of Science and Technology in Taiwan. In August, 2011, she instructed as an assistant professor at the department of Visual Communication Design, the Southern Taiwan University of Science and Technology. Before holding her instruction at the Southern Taiwan University of Science and Technology, she used to instruct at the Asia-Pacific

Institute of Creative Technology and the Tran world Institute of Technology. She has spent a long time endeavoring the development of regional culture industries on the Nantou County and Yunlin County. She also enthusiastically involves in the promotion for the revival of indigenous culture and industries. 